\title{
Pengaruh Latihan Sprint 30 Meter Terhadap Kemampuan Kecepatan Lari Pemain SSB Putra Bumi Serambi KU-15
}

\author{
Ike Siswantara ${ }^{1}$, Deswandi ${ }^{2}$, Bafirman $^{3}$ \\ ${ }^{123}$ Fakultas Ilmu Keolahragaan, Universitas Negeri Padang, Indonesia.
}

E-mail: ikesiswantara@yahoo.com ${ }^{1}$, deswandi@fik.unp.ac.id ${ }^{2}, \underline{\text { bafirman@gmail.com }}{ }^{3}$

\begin{abstract}
Abstrak
Masalah dalam penelitian ini adalah kemampuan kecepatan lari pemain sepakbola SSB Putra Bumi Serambi KU-15 Padang Panjang belum begitu baik. Banyak faktok yang dapat mempengaruhi kemampuan kecepatan lari pemain sepakbola tersebut, diantaranya adalah latihan sprint 30 meter. Tujuan penelitian ini adalah untuk mengetahui pengaruh latihan sprint terhadap kemampuan kecepatan lari pemain sepakbola SSB Putra Bumi Serambi KU-15 Padang Panjang.

Jenis penelitian ini adalah eksperimen. Populasi dalam penelitian ini yaitu pemain sepakbola SSB Putra Bumi Serambi KU-15 Padang Panjang yang berjumlah sebanyak 18 orang. Teknik pengambilan sampel menggunakan total sampling. Dengan demikian jumlah sampel dalam penelitian ini adalah 18 orang. Data dikumpulkan dengan menggunakan pengukuran terhadap kemampuan kecepatan lari

30 meter. Data dianalisis dengan menggunakan uji-t dependent sample.

Hasil penelitian menunjukkan bahwa: Tidak terdapat pengaruh latihan sprint 30 meter secara signifikan terhadap kemampuan kecepatan lari pemain sepakbola SSB Putra Bumi Serambi KU-15 Padang Panjang, dengan hasil analisis thitung $=0,76 \quad$ tabel

$=2,11$, dan diterima kebenarannya secara empiris, serta kecil sekali peningkatan kemampuan kecepatan lari pemain tersebut yaitu hanya sebesar 0,04 yang diperoleh dari dari nilai rata-rata hitung tes awal 4,99 dan tes akhir menjadi 4,95
\end{abstract}

Kata Kunci: Latihan Sprint, Kecepatan Lari, Pemain Sepak Bola 


\begin{abstract}
The problem in this study is the ability to run the speed of soccer players from Putra Bumi Serambi KU-15 Padang Panjang Football Club is not so good. There are many factors that can affect the speed of running the soccer player, including 30 meters sprint training. The purpose of this study was to determine the effect of sprint training on the speed of running ability of Putra Bumi Serambi KU-15 soccer players in Padang Panjang.

This type of research is experimental. The population in this study were soccer players SSB Putra Bumi Serambi KU-15 Padang Panjang which numbered 18 people. The sampling technique uses total sampling. Thus the number of samples in this study were 18 people. Data was collected using measurements of the ability to run 30 meters. Data were analyzed using dependent sample t-test.

The results showed that: There was no significant effect of 30 meters sprint training on the speed of running ability of Putra Bumi Serambi KU-15 Padang Panjang soccer SSB players, with the results of the analysis of t count $=0.76 \quad$ table

$=2.11$, and empirically accepted the truth, as well as a small increase in the ability to

run the player's speed that is only 0.04 which is obtained from the average score of the initial test 4.99 and the final test to 4.95
\end{abstract}

Keywords: Sprint Training, Running Speed, Soccer player

\title{
PENDAHULUAN
}

Kesehatan jasmani memiliki pengaruh yang besar dalam mendukung pembangunan nasional. Oleh karena itu pembangunan saat ini tidak hanya diarahkan pada kualitas pendidikan, peningkatan ekonomi yang lebih baik, tetapi juga diarahkan agar manusianya memiliki jasmani yang sehat pula. Keberhasilan pembangunan disuatu negara tidak terlepas dari kualitas sumber daya manusia yang dimilikinya. Pembangunan pada sektor olahraga saat ini diarahkan untuk mendukung peningkatan kualitas tenaga keolahragaan agar menjadi tenaga yang terampil, cerdas, berkepribadian serta sehat jasmani dan rohani, seperti yang telah dijelaskan dalam UU RI No.03 Tahun2005 pasal 63 ayat 1, bahwa ;"Tenaga keolahragaan terdiri atas pelatih, guru/dosen, wasit, juri, manajer, promotor, administrator, pemandu, penyuluh, instruktur, tenaga medis dan para medis, ahli gizi, ahli 
biomekanika, psikolog atau sebutan lain yang sesuai dengan kekhususannya serta partisipasi dalam penyelenggaraan kegiatan olahraga".

Salah satu olahraga favorit di Indonesia adalah sepakbola. Di kota padang Panjang telah banyak berdiri klub sepakbola atau SSB (Sekolah Sepakbola) salah satu diantaranya adalah SSB Putra Bumi Serambi Padang Panjang. SSB Putra Bumi Serambi Padang Panjang berlatih dilapangan Tabek Gadang yang didirikan oleh Bapak Fikri Aulia Martin S.Pd pada tahun 2014. Meskipun baru didirikan akan tetapi SSB Putra Bumi Serambi Padang Panjang telah memiliki prestasi yang sangat menggembirakan. Prestasi SSB Putra Bumi Serambi Padang Panjang dapat dilihat dalam.

Turnamen junior mewakili sumatera barat dalam ajang Danone Cup di Palembang. Dalam pertandingan turnamen Sumbar Riau Cup SSB Putra Bumi Serambi menduduki peringkat ke tiga. Dalam pertandingan turnamen antar SSB se Sumatera Barat menduduki peringkat runer up .selain itu SSB Putra Bumi Serambi letah melahirkan pemain-pemain yang sangat berprestasi. Untuk mempertahankan atau meningkatkan prestasi SSB Putra Bumi Serambi Padang Panjang selain teknik dan taktik, yang cukup dominan dalam meningkatkan prestasi pada cabang sepakbola adalah kondisi fisik.

Pada cabang olahraga sepakbola membutuhkan kondisi fisik yang kompleks baik itu kekuatan, kecepatan, kelenturan, daya tahan, kordinasi bahkan gabungan dari komponen kondisi fisik itu sendiri seperti; power (gabungan dari kekuatan dan kecepatan), daya tahan kekuatan (gabungan dari kekuatan dan daya tahan), kelincahan (gabungan dari kecepatan dan kelenturan). Dalam permainan sepakbola, kecepatan sangat di perlukan karena dalam merebut bola seelain kelincahan dan penguasaan teknik.

Menurut Syafruddin "Kecepatan diartikan sebagai kemampuan dalam melakukan gerakangerakan dalam satuan waktu tertentu yang ditentukan oleh fleksibelitas tubuh melalui sistem pensyarafan dan kinerja otot”. Di dalam permainan sepakbola sangat di perlukan kecepatan. Salah satu di bentuk di perlukannya saat pemain mengejar bola yang sedang digiring oleh lawan atau ketika pemain berlari dengan kecepatan tinggi untuk menerima bola crossing dari teman satu tim, begitu juga dalam melakukan gerakan menggiring bola untuk melewati pemain lawan atau menuju daerah pertahan lawan.

Berdasarkan observasi dan informasi dari pelatih SSB Bumi Putra Serambi Padang Panjang kecepatan lari pemain muda SSB Putra Bumi Serambi Padang Panjang masih belum begitu baik, hal ini terlihat dari beberapa dalam pelaksanaan teknik seperti menggiring bola, menerima bola operan dari teman sendiri, kalah cepat ketika menghalau bola dari daerah pertahanan sendiri, dan sebagainya. Lari cepat atau sprint adalah lari dengan tolakan secepat-cepatnya menurut Dikdik Zafar Sidik (2010:2). Artinya seorang pemain sepakbola harus mempunyai kemampuan untuk berlari secepat- 
cepatnya dengan tolakan yang cepat.

Dari kenyataan tersebut peneliti menduga ada beberapa faktor yang mempengaruhi kemampuan kecepatan lari pemain SSB Putra Bumi Serambi Padang Panjang antara belum maksimalnya latihan kecepatan misalnya latihan sprint 30 meter, latihan sprint 40 meter dan latihan sprint 50 meter. Berdasarkan masalah yang dikemukakan seperti yang telah di uraikan sebelumnya, peneliti bermaksud ingin melakukan suatu penelitian yang berkaitan dengan factor yang dominan mempengaruhi kemampuan kecepatan lari pemain sepakbola SSB Bumi Putra Serambi Padang Panjang. Dengan penelitian ini nantinya diharapkan pemain sepakbola SSB Bumi Putra Serambi Padang Panjang tersebut dapat mengatasi masalah yang terjadi yang disebabkan oleh kemampuan kecepatan lari yang banyak dibutuhkan dalam permainan sepakbola.

Permainan sepakbola adalah salah satu cabang olahraga yang sangat populer di dunia. Dari sejarah sepakbola lahir dan berkembang sejak lama. Perkembangan ini sudah di mulai oleh suku bangsa cina yang telah memainkan olahraga ini sekitar 1000 tahun sebelum masehi, yang di sebut tsu chiu. Pada Abad ke-14, di Jepang juga sepakbola yang di beri nama "kamari”. Permainan ini dimainkan pada lapangan yang berukuran 14x14 meter. Sedangkan di Italia pada tahun 1530, telah dimainkan suatu permainan yang diberinama "Giugo De Calcio", yang bermakna bermain dengan sepakan Muctar, (1992: 83) dalam Pino Hardi(2016:9).

Pengertian teknik dasar sepakbola adalah semua kegiatan yang mendasar permainan sehinga dengan modal demikin seseorang sudah dapat bermain sepakbola. Pada saat bermain, pemain yang mengolah bola hanya satu orang sedangkan pemain yang lain akan melakukan gerakan, baik selaku penyerang maupun pemain bertahan Tim Mata Kuliah Sepakbola FIK UNP (2011:125). Unsur kondisi fisik yang mempengaruhi permainan sepakbola Kekuatan, Daya tahan, Kelincahan, Kelentukan, Koordinasi, Kecepatan.

Berkaitan dengan kecepatan lari, Eddy Purnomo (2011) dalam Sri Nur Widayati (2012:27), menyatakan bahwa: Pengertian lari jarak pendek adalah lari yang menempuh jarak antara 50 meter sampai dengan jarak 400 meter. Kecepatan dalam berlari jarak pendek adalah hasil kontraksi yang kuat dan cepat dari otot-otot yang dirubah menjadi gerakan halus, lancar dan efesien sangat dibutuhkan bagi pelari untuk mendapatkan kecepatan maksimal.

Menurut Grosser, Starickha, dan Zimmerman dalam Pasurney (2001:1), "latihan itu berkaitan dengan usaha untuk: 1) meningkatkan prestasi, 2) mempertahankan prestasi”, hal ini bahwa latihan itu bertujuan untuk meningkatkan prestasi dan mempertahankan prestasi dan seorang atlet agar tidak terjadi penurunan prestasi. Jadi, dengan latihan itu tujuannya bukan hanya untuk 
meningkatkan prestasi akan tetapi juga mempertahankannya.

Menurut Arsil (2000),menyatakan kecepatan sebagai "suatu kemampuan bersyarat untuk menghasilkan gerakan tubuh dalam waktu sesingkat mungkin. Kebuatan otot, Viskositas otot, Kecepatan reaksi, Kecepatan kontraks, Kordinasi, Ciri-ciri antropometri, Daya tahan aneorobikumum atau daya tahan kecepatan. Menurut Lezerlter dalam Syafruddin (2016) metode latihan kecepatan sangat tergantung pada kebutuhan dan karakteristik olahraganya serta tingkat pengaruh kekuatan,dayatahan dan teknik olarahraganya Latihan kecepatan aksi dan kecepatan reaksi, latihan kekuatan kecepatan, latihan kecepatan maksimal, lari daya tahan kecepatan. Intensitas rangsangan, durasi rangsangan, volume ransangan, frekuensi ransangan, interval istirahat,ulangan,sistem energi.

\section{METODE}

Jenis penelitian ini adalah eksperimen semu yaitu yang bertujuan untuk mengungkapkan pengaruh antara variabel bebas terhadap variabel terikat (Sugiono,2011:74). Populasi dan Sampel Penelitian. populasi adalah generalisasi yang terjadi atas objek atau subjek yang memiliki kualitas dan karakteristik tertentu yang ditetapkan oleh peneliti untuk dipelajari dan kemudian ditarik kesimpulannya. Populasi penelitian ini adalah pemain SSB Putra Bumi Serambi KU-15 kota Padang Panjang yang berjumlah 18 orang.

Sampel secara sederhana diartikan bagian dari populasi yang menjadi sumber data yang sebenarnya dalam suatu penelitian. Dalam penelitian ini teknik pengambilan sampel adalah total sampling. Menurut Sugiyono (2013:124)" total sampling adlah teknik penentuan sampel dengan cara mengambil seluruh anggota populasi sebagai responden atau sampel”. Jadi sampel dalam penelitian ini adalah seluruh pemain SSB Putra Bumi Serambi KU-15 yang berjumlah 18 orang.

\section{HASIL DAN PEMBAHASAN}

\section{Hasil Penelitian}

1. Tes Awal Kemampuan kecepatan lari

Berdasarkan temuan penelitian dari 18 orang pemain, yang berada pada kelas interval 4,20 - 4,54 yaitu ada 5 orang (27,78\%), kelas interval 4,55 - 4,89 tidak ada satu orangpun yang memilikinya dan kelas interval 4,90 - 5,24 adalah sebanyak 9 orang (50\%). Selanjutnya untuk kelas interval 5,25 - 5,59 yaitu 3 orang (16,67\%) dan kelas interval 5,60

$-5,94$ yakni hanya 1 orang $(5,56 \%)$. 


\section{Tes akhir kemampuan kecepatan lari}

Berdasarkan temuan penelitian dari 18 orang pemain SSB Putra Bumi Serambi Ku-15 Padang Panjang, yang berada dalam kelas interval 4,09-4,47 adalah 4 orang $(22,22 \%)$, kelas interval 4,48 - 4,86 yaitu 2 orang (11,11\%), dan kelas interval 4,87 - 5,25 ditemukan sebanyak 8 orang $(44,44 \%)$. Selanjutnya untuk kelas interval 5,26 - 5,64 adalah 2 orang $(11,11 \%)$ dan kelas interval $5,65-6,03$ juga ada 2 orang $(11,11 \%)$.

Berdasarkan uraian tentang hasil data tes akhir kemampuan kecepatan lari dari 18 orang pemain SSB Putra Bumi Serambi Ku-15 Padang Panjang, setelah diberikan latihan sprint 30 meter, maka ditemukan pemain yang memiliki kemampuan kecepatan lari dengan skor di atas kelompok rata-rata adalah 7 orang $(38,89 \%)$ dan skor dalam kelompok rata-rata tidak ada satu orangpun yang memilikinya. Sedangkan pemain SSB Putra Bumi Serambi Ku-15 Padang Panjang, untuk di bawah skor kelompok rata-rata yaitu ditemukan sebanyak 11 orang $(61,11 \%)$.

Di dalam penelitian ini terlebih dahulu di lakukan uji persyaratan analisis dengan uji normalitas data untuk mengetahui apakah data dari variabel yang diteliti berdistribusi normal atau tidak dapat digunakan uji Lilliefors dengan taraf signifikansi $>0,05$.Hipotesis uji Lilliefors:

Ho $\quad$ : Lobservasi $<$ Ltabel data berdistribusi normal

$\mathrm{H}_{\mathrm{a}} \quad$ : Lobservasi $>$ Ltabel data tidak berdistribusi normal

\begin{tabular}{|c|c|c|c|}
\hline$\overline{\text { Data }}$ & & LoOservasi Ltabel & Ket \\
\hline Kemampuan & kecepatan lari (Tes Awal) & 0,163 & Nornal \\
\hline Kemampuan & kecepatan lari (Tes Akhir) & 0,104 & Normal \\
\hline
\end{tabular}

Menujukkan bahwa hasil pengujian untuk data tes awal kemampuan kecepatan lari adalah Lobservasi $0,163<$ Ltabel0,200, artinya data berdistribusi normal dan hasil pengujian untuk data tes akhir kemampuan kecepatan lari adalah Lobservasi0,104 < Ltabel0,200

dapat disimpulkan bahwa data berdistribusi normal. 0.05). Setelah uji persyaratan analisis dilakukan dan ternyata semua data variabel penelitian memenuhi persyaratan untuk dilakukan pengujian statistik lebih lanjut yaitu pengujian hipotesis. Berikut dideskripsikan hasil pengujian terhadap hipotesis penelitian yaitu: Terdapat pengaruh latihan sprint 30 meter terhadap kemampuan kecepatan lari pemain SSB Putra Bumi Serambi Ku-15 Padang Panjang.

Uji statistik yang digunakan adalah t-test yaitu melihat pengaruh dari rata-rata hitung dalam satu 
kelompok yang sama dengan taraf signifikan 0,05 . Hasil tes awal kemampuan kecepatan lari, dengan menggunakan latihan sprint 30 meter dengan jumlah sampel 18 orang diperoleh rata-rata hitung yaitu 4,99 dan simpangan baku adalah 0,48. Sedangkan untuk nilai rata-rata hitung tes akhir adalah 4,95 dan simpangan baku 0,53 .

\begin{tabular}{|c|c|c|c|c|}
\hline Kemampuan kecepatan lari & Mean SD & thitung ttabel & Hasil Uji & Ket \\
\hline Tes Awal & 4,99 & & Tidak & Ho Diterima \\
\hline Tes Akhir & 4,95 & 0,76 & Signifikan & dan Ha ditolak \\
\hline
\end{tabular}

Berdasarkan tabel dapat dilihat bahwa thitung $=0,76 \quad$ tabel $=2,11$. Hal ini berarti bahwa hipotesis penelitian tidak dapat diterima/ditolak. Dengan demikian dapat disimpulkan bahwa latihan sprint 30 meter tidak memberikan pengaruh yang signifikan terhadap kemampuan kecepatan lari pemain SSB Putra Bumi Serambi Ku-15 Padang Panjang. Namun apabila dilihat dari nilai rata-rata memang terjadi ada peningkatan kemampuan kecepatan lari tersebut hanya 0,04 yaitu dari skor rata-rata (mean) tes awal 4,99 dan skor rata-rata (mean) tes akhir menjadi 4,95.

\section{KESIMPULAN}

Tidak terdapat pengaruh latihan sprint 30 meter secara signifikan terhadap kemampuan kecepatan lari pemain SSB Putra Bumi Serambi Ku-15 Padang Panjang, dengan hasil analisis thitung $=0,76 \quad$ tabel $=2,11$, dan diterima kebenarannya secara empiris, serta peningkatan kemampuan kecepatan lari pemain tersebut hanya sebesar 0,04 yaitu dari nilai rata-rata hitung tes awal 4,99 dan tes akhir menjadi 4,95. yang telah dikemukakan di atas, maka disarankan kepada: Pelatih sepakbola di SSB Putra Bumi Serambi Ku-15 Padang Panjang agar menggunakan bentukbentuk latihan lain selain latihan sprint 30 meter, sehinga kemampuan kecepatan lari dapat ditingkatkan.

Pemain SSB Putra Bumi Serambi Ku-15 Padang Panjang, agar lebih giat lagi melakukan latihan-latihan komponen-komponen kondisi fisik yang dominan dibutuhkan untuk meningkatkan kemampuan kecepatan lari, jadi tidak hanya dengan latihan sprint 30 meter sajPengurus SSB Putra Bumi Serambi Ku-15 Padang Panjang, agar memberikan dukungan misalnya hadir bersama pemain sepakbola di lapangan sehingga pemain giat dan rajin dalam berlatih.

\section{DAFTAR RUJUKAN}


Sport Science: Jurnal Sain Olahraga dan Pendidikan Jasmani ISSN 114-562X (Cetak), ISSN XXXX-XXXX(Online)

http://sportscience.ppj.unp.ac.id/index.php/jss/index

Arsil, 2000. Pembentukan kondisi fisik. Padang:FIK UNP.

Muchtar,remmy, 1992. Olahraga pilihan sepakbola. Depdikbud proyek pembinaan tenaga kependidikan.

Sidik,Dikdik Zafar.2010. Mengajar dan melatih atletik. Bandung : PT. Remaja Rosdakarya.

Sugiono, 2011. Metode penelitian kualitatif kuntutatif dan R\&D. Bandung: alfabeta.

Syafruddin, 2016. Perangkat pembelajaran ilmu melatih dasar. Padang: FIK UNP. Tim pengajarsepakbola, 2003. Buku ajar sepakbola. Padang: FIK UNP.

Yulifri, Arsil, 2011. Permainan sepakbola. Padang: FIK UNP. 